\title{
Dietas com nitrogênio não-proteico para fêmeas bovinas superovuladas sem prévia adaptação durante curto tempo e em diferentes fases do ciclo estral ${ }^{1}$
}

\author{
Flávio Rocha Alves ${ }^{2}$, Claudiney de Melo Martins ${ }^{3}$, Fernando do Amaral Braga ${ }^{3}$, Ricardo Lopes \\ Dias da Costa ${ }^{4}$, João José Assumpção de Abreu Demarchi ${ }^{4}$, Paulo Henrique Mazza Rodrigues ${ }^{2}$ \\ 1 Projeto financiado pela Fundação de Amparo à Pesquisa do Estado de São Paulo (FAPESP). \\ 2 Departamento de Nutrição e Produção Animal, Faculdade de Medicina Veterinária e Zootecnia, Universidade de São Paulo, Pirassununga, SP, Brasil. \\ ${ }^{3}$ Departamento de Reprodução Animal, Faculdade de Medicina Veterinária e Zootecnia, Universidade de São Paulo, São Paulo, SP, Brasil. \\ ${ }^{4}$ Agência Paulista de Tecnologia dos Agronegócios (APTA), Regional Extremo Oeste, Andradina, SP, Brasil.
}

RESUMO - Objetivou-se neste estudo avaliar o efeito do fornecimento, sem prévia adaptação, durante curto tempo e em diferentes fases do ciclo estral, de dietas contendo nitrogênio não-proteico (NNP) na produção, na qualidade e no grau de desenvolvimento de embriões recuperados em fêmeas bovinas superovuladas. Sessenta e oito vacas Nelore foram distribuídas em três grupos: um controle e dois com fornecimento de ureia antes (UA $=$ do dia -5 ao dia 0 ) e após (UD $=$ dia 0 ao dia 5 ) a inseminação artificial. As vacas foram mantidas em pastagem e receberam concentrado (3,0 kg/animal/dia) durante 16 dias. Foram formulados dois concentrados, e as dietas totais (concentrado e consumo estimado de pastagem) apresentaram $12,0 \%$ (dieta controle) e 14,6\% (dieta NNP) de proteína bruta (PB). As vacas foram sincronizadas, superovuladas e inseminadas. Sete dias (dia 7) após a inseminação (dia 0), realizou-se a colheita e análise dos embriões. Amostras de sangue foram coletadas nos dias $-5,0$ e 5 para determinação da concentração de nitrogênio ureico plasmático (NUP), glicose, insulina e progesterona. A época de fornecimento de ureia influenciou as concentrações médias de NUP nos dias $-5,0$ e 5 , mas não tiveram efeito nas concentrações de glicose, insulina e progesterona. O período de fornecimento da ureia teve efeito na porcentagem de mórulas compactas em relação ao total de estruturas $(\mathrm{UA}=51,4$ vs. $\mathrm{UD}=15,3 \%)$, em relação ao total de oócitos fecundados $(\mathrm{UA}=$ 62,5 vs. $\mathrm{UD}=30,6 \%$ ) e em relação ao total de embriões viáveis (UA = 68,8 vs. UD = 38,6\%). No grupo que recebeu ureia depois da inseminação artificial, houve redução de $70,2 \%$ da proporção de mórulas compactas por total de estruturas em relação ao grupo que recebeu ureia antes da inseminação. Dietas com nitrogênio não-proteico fornecidas imediatamente após a inseminação promovem aceleração do desenvolvimento embrionário inicial.

Palavras-chave: embrião, Nelore, nitrogênio ureico plasmático (NUP), proteína bruta, ureia

\section{Effect of short term non-protein nitrogen feeding for superovulated beef cows without previous adaptation and at different periods of the oestrus cycle}

ABSTRACT - The aim of this study was to evaluate the effects of short term non-protein nitrogen feeding at different periods of the oestrus cycle in superovulated cows, without previous adaptation, on yield, quality and development degree of recovered embryos. A total of sixty-eight Nelore cows were distributed in three groups: the control group (C) and two groups with urea supply before (UB; urea supply from day -5 to day 0 ) and after (UA; supply from day 0 to day 5) artificial insemination. Animals were kept grazing and received $3.0 \mathrm{~kg} /$ animal/day of concentrate during 16 days. Two concentrates were formulated and the total diets (concentrate and estimate forage intake) showed 12.0\% (control diet) and 14.6\% (non-protein diet) of crude protein. Animals were synchronized, superovulated and inseminated. The embryos were collected and analysed seven days (day 7) after insemination (day 0). Blood samples were collected on days $-5,0$ and 5 to determine concentration of plasmatic urea nitrogen, glucose, insulin and progesterone. The time of urea supply affected average plasmatic urea nitrogen concentration on days $-5,05$ but it did not affect concetrations of glucose, insulin and progesterone. The moment of urea inclusion had effect on compact morula percentage in relation to the total number of structures ( $\mathrm{UB}=51.4 \mathrm{vs}$. UA $=15.3 \%$ ), to the total number of fertilized oocytes $(\mathrm{UB}=62.5 \mathrm{vs} . \mathrm{UA}=30.6 \%)$ and to the total number of viable embryos $(\mathrm{UB}=68.8 \mathrm{vs}$. $\mathrm{UA}=38.6 \%)$. In the after insemination group of urea supply there was $70.2 \%$ of reduction on compact morula proportion over the total structures in relation to the group that received urea before insemination. Non-protein nitrogen feeding immediately after insemination promotes faster rates of embryo development.

Key Words: crude protein, embryo, Nelore, plasmatic urea nitrogen (PUN), urea 


\section{Introdução}

Excesso de proteína na dieta de ruminantes pode desencadear aumento na concentração de nitrogênio ureico plasmático. Concentrações acima de $19 \mathrm{mg} / \mathrm{dL}$ são associadas a baixo desempenho reprodutivo (Butler et al., 1996). Ressaltam-se quatro teorias envolvidas no contexto para explicar essa associação.

A primeira remete à relação entre a diminuição da concentração de progesterona sistêmica e a alta proteína bruta na dieta (Jordan \& Swanson, 1979). Além disso, o balanço energético negativo pode ser acentuado pela alta PB, devido ao alto custo energético da detoxificação da amônia (Staples et al., 1993) e, dependendo da intensidade do balanço energético negativo, indiretamente, pode haver inibição da progesterona (Butler, 2000).

A segunda teoria infere que a amônia e/ou a ureia circulante alteram a atividade secretória uterina, causando mudanças nas concentrações iônicas (Jordan et al., 1983) e no pH (Rhoads et al., 2004) durante a fase luteal.

A terceira preconiza que o efeito negativo do alto NUP esteja restrito entre a fase de maturação do oócito e o desenvolvimento inicial do embrião. De Wit et al. (2001) observaram impedimento da meiose durante a fase de maturação do oócito. Zander et al. (2006) afirmaram que embriões apresentam maior suscetibilidade na fase inicial de clivagem. Além disso, a amônia causa diminuição na taxa de crescimento de células da granulosa (Rooke et al., 2004).

A quarta teoria refere-se ao maior metabolismo e à aceleração do crescimento dos embriões. Embriões obtidos de fêmeas alimentadas com excesso de PB apresentaram-se metabolicamente mais ativos (McEvoy et al., 1997), com maior síntese proteica "de novo" (Sinclair et al., 2000b) e melhor desenvolvimento (Hammon et al., 2000). Além disso, o transporte inicial do embrião no oviduto pode ser alterado pela alta PB na dieta. Embriões mais maduros antes da entrada no útero podem levar a uma assincronia entre mudanças uterinas e mudanças embrionárias necessárias para o reconhecimento materno da gestação (Berardinelli et al., 2001).

Nesta pesquisa, objetivou-se verificar o efeito da proteína bruta na dieta sobre a eficiência reprodutiva de vacas Nelore a pasto para testar a hipótese de que o fornecimento de dietas contendo nitrogênio não-proteico (NNP) sem prévia adaptação, durante curto tempo e em diferentes fases do ciclo estral, causaria diminuição na quantidade, na qualidade e no grau de desenvolvimento dos embriões recuperados.

\section{Material e Métodos}

Foram utilizadas 68 vacas Nelore com escore corporal de 7,56 $\pm 0,92$ (escala de 1 a 9 , em que $1=$ magra e $9=$ obesa), pesando $557,6 \pm 101,1 \mathrm{~kg}$, distribuídas em três grupos: um controle e dois com épocas diferentes de fornecimento de ureia; $\mathrm{UA}=$ ureia antes do dia 0 (fornecimento de dieta com ureia do dia -5 ao dia 0 do protocolo hormonal de superovulação) e UD = ureia depois do dia 0 (fornecimento de dieta com ureia do dia 0 ao dia 5).

O delineamento experimental utilizado foi de blocos ao acaso, com os blocos formados de acordo com o grupo de colheita de embriões. Foram formados 3 períodos de colheita, o primeiro composto por 19 animais, o segundo por 20 e o terceiro, por 29 animais. Os grupos controle e com recebimento de ureia antes e após a inseminação artificial foram casualizados entre os animais de cada período.

As vacas foram mantidas em piquetes com pastagem de Brachiaria brizantha cv. Marandu e receberam concentrado (3,0 kg/animal/dia) durante 16 dias. Foram formulados dois concentrados, e as dietas totais, compostas de concentrado e consumo estimado de pastagem (Tabela 1), continham 12,0\% (dieta controle) ou $14,6 \%$ de PB (dieta com NNP). A diferença na PB entre as dietas foi o acréscimo de ureia $(100 \mathrm{~g} / \mathrm{vaca} / \mathrm{dia})$ nos dias referidos, enquanto nos outros dias, todos os animais receberam a mesma dieta do grupo controle. A dieta controle foi formulada para garantir o nível de manutenção de

Tabela 1 - Composição das dietas, com base na matéria seca

\begin{tabular}{|c|c|c|}
\hline \multirow[t]{2}{*}{ Ingrediente $(\%)$} & \multicolumn{2}{|c|}{ Dieta } \\
\hline & Controle & NNP \\
\hline Pastagem estimada & 74,06 & 74,06 \\
\hline Milho moído & 9,20 & 8,23 \\
\hline Farelo de soja & 14,13 & 14,13 \\
\hline Ureia $(45 \%)$ & - & 0,97 \\
\hline Calcário calcítico & 0,48 & 0,48 \\
\hline Sal branco & 0,19 & 0,19 \\
\hline Mistura mineral ${ }^{1}$ & 1,94 & 1,94 \\
\hline \multicolumn{3}{|l|}{ Composição } \\
\hline Proteína bruta $(\%)$ & 12,0 & 14,6 \\
\hline $\begin{array}{l}\text { Proteína degradável no rúmen } \\
(\% \text { proteína bruta) }\end{array}$ & 70,0 & 76,0 \\
\hline $\begin{array}{l}\text { Proteína não-degradável no rúmen } \\
(\% \text { proteína bruta) }\end{array}$ & 30,0 & 24,0 \\
\hline Fibra em detergente ácido (\%) & 29,3 & 29,3 \\
\hline Fibra em detergente neutro (\%) & 56,2 & 56,1 \\
\hline Extrato etéreo $(\%)$ & 1,6 & 1,6 \\
\hline Energia metabolizável (Mcal/kg MS) & 2,2 & 2,2 \\
\hline Energia líquida de lactação (Mcal/kg MS) & 1,4 & 1,4 \\
\hline Nutrientes digestíveis totais (\% MS) & 56,1 & 56,0 \\
\hline
\end{tabular}


proteína degradável no rúmen, enquanto que a dieta com NNP possuía 1,25 vez o nível de manutenção de proteína degradável no rúmen (NRC, 1996). Ambas foram isocalóricas.

Os protocolos de sincronização e superovulação utilizados foram semelhantes ao descrito por Baruselli et al. (2006), com início no dia -8 (D-8) com a colocação do implante vaginal contendo $1,0 \mathrm{~g}$ de progesterona $\left(\right.$ Crestar $^{\circledR}$, Intervet, Brasil), seguido pela injeção por via intramuscular de 2,0 mg de benzoato de estradiol (Estrogin ${ }^{\circledR}$, Farmavet, Brasil). Entre o dia -4 (D-4) e o dia -1 (D-1) foram administradas, duas vezes ao dia, via intramuscular, doses decrescentes de FSH (Pluset ${ }^{\circledR}$, IF Serono, Itália), manhã e à tarde, totalizando $250 \mathrm{UI}$ de FSH por vaca. O implante vaginal de progesterona foi retirado ao mesmo tempo da última aplicação de FSH (D-1). No dia -2 (D-2) foram administrados $2 \mathrm{~mL}$, via intramuscular de Preloban ${ }^{\circledR}$ (150 mg de D-cloprostenol; Intervet, Brasil), simultaneamente, à administração de Pluset pela manhã, e $1 \mathrm{~mL}$ à tarde. Oito dias após o início da sincronização, ou seja, no dia 0, foram administrados 2,5 mL de Fertagyl ${ }^{\circledR}$ (via intramuscular, $25 \mathrm{mg}$ de GnRH; Intervet, Brasil) pela manhã. Neste mesmo dia, 12 horas após a aplicação do indutor de ovulação (Fertagyl), foi realizada a primeira inseminação artificial em tempo fixo (IATF). No outro dia pela manhã (D1), realizou-se a segunda inseminação artificial. O sêmen utilizado foi de um mesmo doador e a inseminação artificial realizada pelo mesmo inseminador em todas as fêmeas. A colheita dos embriões foi realizada por método nãocirúrgico no sétimo dia após a primeira inseminação (D7).

A avaliação da qualidade e do grau de desenvolvimento dos embriões foi determinada segundo o manual da IETS (Stringfellow \& Seidel, 1998).

Amostras de sangue foram coletadas no momento do fornecimento das dietas $(0 \mathrm{~h}), 3$ e 6 horas após a alimentação nos dias $-5,0$ e 5 . As colheitas das amostras de sangue foram realizadas em duplicata, por punção da veia jugular, utilizando-se tubos a vácuo contendo EDTA, para posterior determinação das concentrações de NUP e glicose; e tubos a vácuo sem anticoagulante, somente na hora zero, com a finalidade de determinar as concentrações de insulina e progesterona. Imediatamente após a colheita, foi realizada a separação do plasma ou soro sanguíneo por centrifugação (2000 g) durante 20 minutos. As amostras de plasma, assim como as de soro, foram congeladas em tubos do tipo ependorf, logo após a centrifugação.

Para determinação da glicose plasmática foi utilizado o método enzimático-colorimétrico, descrito por Trinder (1969) e Henry et al. (1974), utilizand-seo kit comercial $\left(\mathrm{CAT} \mathrm{n}^{\mathrm{O}} 02200\right.$, Laborlab $\left.{ }^{\circledR}\right)$ adaptado para leitura em tubos no aparelho do tipo espectrofotômetro (Quick Lab, Drake ${ }^{\circledR}$ ), com comprimento de luz de 500 nanômetros.

O nitrogênio ureico plasmático foi determinado pelo método enzimático colorimétrico, descrito por Henry (1968) e Hallet e Cook (1971), utilizando-se kit comercial (CAT $\mathrm{n}^{0}$ 02800, Laborlab $\left.{ }^{\circledR}\right)$ adaptado para leitura em tubos no aparelho do tipo espectrofotômetro (Quick Lab, Drake ${ }^{\circledR}$ ), com comprimento de luz de 620 nanômetros.

A concentração de progesterona sérica foi determinada em duplicata, pela técnica de radioimunoensaio, utilizando-se kit comercial CAC em fase sólida (Progesterone Coat-aCount ${ }^{\circledR}$, Diagnostics Products Co., Los Angeles, CA, USA). Foram utilizados dois controles de qualidade, os padrões do kit nas concentrações de $0,1 \mathrm{ng} / \mathrm{mL}$ e $20 \mathrm{ng} / \mathrm{mL}$, em duplicata, ao início e fim de cada ensaio.

A concentração sérica de insulina foi estabelecida pela técnica de radioimunoensaio, utilizando-se o kit comercial CAC em fase sólida (Insulina Coat-a-Count ${ }^{\circledR}$, Diagnostics Products Co., Los Angeles, Ca, USA) e dois controles de qualidade e os padrões do kit nas concentrações de 15 e $100 \mu \mathrm{UI} / \mathrm{mL}$, em duplicata, ao início e fim de cada ensaio.

O coeficiente de variação médio aceito dentro destes ensaios foram de até $5 \%$ entre as determinações.

Os dados foram analisados pelo programa SAS (2001), e os resultados de produção, qualidade e grau de desenvolvimento dos embriões separados em dois contrastes ortogonais: efeito da inclusão de ureia na dieta [C vs. (UA + UD)] e efeito do momento de inclusão da ureia na dieta (UA vs. UD). Na análise dos dados de NUP, glicose plasmática, insulina e progesterona, adotou-se análise de variância com medidas repetidas no tempo e, na presença de interação tempo e tratamento, estudou-se o efeito de tratamento dentro do tempo pelo teste de média Tukey utilizado-se o nível de significância de 5\% para todos os testes realizados.

\section{Resultados e Discussão}

Para as concentrações de nitrogênio ureico plasmático, houve efeito de interação entre horas de colheita e época do fornecimento de ureia nos dias -5 $(\mathrm{P}=0,0044)$ e $0(\mathrm{P}<0,0001)$, mas não no dia $5(\mathrm{P}=0,1923)$ (Tabela 2). Para esta variável, também houve efeito de hora de colheita nos dias $-5(\mathrm{P}<0,0001), 0(\mathrm{P}<0,0001)$ e 5 $(\mathrm{P}=0,0028)$. Além disso, houve efeito de interação entre dias de colheita e época de fornecimento de ureia ( $\mathrm{P}=0,0005)$ e efeito do dia de colheita $(\mathrm{P}<0,0001)$. Adicionalmente houve efeito de época de fornecimento da ureia nos valores médios de NUP no dia -5 ( $\mathrm{P}=0,0007)$, 
Tabela 2 - Concentração de nitrogênio ureico plasmático (em $\mathrm{mg} / \mathrm{dL}$ ) nos dias $-5,0$ e 5

\begin{tabular}{|c|c|c|c|c|c|c|c|}
\hline \multirow[b]{2}{*}{ Dias } & \multirow[b]{2}{*}{ Horas } & \multicolumn{3}{|c|}{ Época do fornecimento } & \multirow[b]{2}{*}{ Média } & \multirow[b]{2}{*}{ CV $(\%)$} & \multirow[b]{2}{*}{ Probabilidade } \\
\hline & & Controle & Ureia antes & Ureia depois & & & \\
\hline \multirow{4}{*}{ D-5 } & $0 \mathrm{~h}$ & 15,51 & 15,61 & 13,97 & 15,02 & 37,9 & 0,4890 \\
\hline & $3 \mathrm{~h}$ & 16,87 & 18,45 & 14,78 & 16,70 & 46,3 & 0,0688 \\
\hline & $6 \mathrm{~h}$ & $16,14 \mathrm{ab}$ & $19,10 \mathrm{a}$ & $14,66 \mathrm{~b}$ & 16,64 & 40,6 & 0,0055 \\
\hline & Média & $16,18 \mathrm{ab}$ & $17,72 \mathrm{a}$ & $14,47 b$ & 16,12 & 42,1 & 0,0007 \\
\hline \multirow{4}{*}{ D0 } & $0 \mathrm{~h}$ & $17,97 b$ & $23,03 \mathrm{a}$ & $18,93 \mathrm{ab}$ & 20,01 & 34,5 & 0,0134 \\
\hline & $3 \mathrm{~h}$ & 19,75 & 23,31 & 22,16 & 21,77 & 32,4 & 0,1238 \\
\hline & $6 \mathrm{~h}$ & 19,14 & 21,79 & 22,35 & 21,12 & 33,3 & 0,1314 \\
\hline & Média & $18,95 b$ & $22,71 \mathrm{a}$ & $21,15 \mathrm{ab}$ & 20,97 & 33,4 & 0,0010 \\
\hline \multirow{4}{*}{ D5 } & $0 \mathrm{~h}$ & 20,35 & 18,68 & 21,00 & 20,00 & 28,6 & 0,1117 \\
\hline & $3 \mathrm{~h}$ & $20,72 \mathrm{ab}$ & $19,19 b$ & $22,45 \mathrm{a}$ & 20,79 & 30,8 & 0,0421 \\
\hline & $6 \mathrm{~h}$ & 21,74 & 19,35 & 21,09 & 20,71 & 31,3 & 0,2485 \\
\hline & Média & $20,93 \mathrm{a}$ & $19,08 \mathrm{~b}$ & $21,51 \mathrm{a}$ & 20,50 & 30,2 & 0,0022 \\
\hline
\end{tabular}

Médias com sobrescritos diferentes na mesma linha diferem $(\mathrm{P}<0,05)$ pelo teste Tukey.

no dia $0(\mathrm{P}=0,0010)$ e no dia $5(\mathrm{P}=0,0022)$. A maior concentração de NUP no dia -5 foi observada nos animais que receberam dietas contendo ureia antes do dia 0 , que diferiram daqueles que receberam ureia após a inseminação, mas não do grupo controle. No dia 0 , os animais que receberam ureia antes da inseminação mantiveram o maior valor, diferindo apenas dos animais controle, mas não daqueles que receberam ureia após a inseminação. Já no dia 5, aqueles que receberam ureia somente após a inseminação passaram a apresentar a maior concentração de NUP, diferindo somente daqueles que receberam ureia antes da inseminação.

Elrod \& Butler (1993) verificaram que 50\% acima dos níveis da exigência de PDR em novilhas holandesas aumentaram a concentração de NUP de $10,2 \mathrm{mg} / \mathrm{dL}$ para $14,8 \mathrm{mg} / \mathrm{dL}$. Neste estudo, houve excesso de $25 \%$ sobre os níveis de exigência de PDR na dieta contendo NNP na forma de ureia, enquanto a dieta controle atendia às exigências (NRC, 1996). McEvoy et al. (1997) forneceram dietas com 0,15 e $30 \mathrm{~g}$ de ureia para ovelhas e encontraram valores de NUP de 5,6;14,4 e 20,0 mg/dL, respectivamente. Semelhantemente, Kenny et al. (2002a) forneceram 0 ou $240 \mathrm{~g}$ de ureia para novilhas de corte e obtiveram 11,4 e $25,4 \mathrm{mg} / \mathrm{dL}$ de NUP, respectivamente. Sinclair et al. (2000a) utilizaram dietas isoproteicas (15\% de PB) com variações apenas na taxa de liberação de nitrogênio no rúmen e encontraram 16,1 e 19,7 mg/dL em novilhas com dietas com baixa e alta liberação, respectivamente. Kenny et al. (2001), utilizando novilhas de corte a pasto com concentrações alta ou baixa de nitrogênio no pasto, obtiveram concentrações de NUP de 18,7 e 7,9 mg/dL, respectivamente. Incrementos lineares nas concentrações séricas de nitrogênio ureico também foram observados com o aumento das concentrações de ureia na dieta (Rennó et al., 2008) ou no suplemento proteico oferecido a animais a pasto (Moraes et al., 2009).

Para os teores plasmáticos de glicose, não houve interação entre hora de colheita e época de fornecimento de ureia nos dias $-5(\mathrm{P}=0,5044), 0(\mathrm{P}=0,8248)$ e $5(\mathrm{P}=0,2176)$

Tabela 3 - Teores de glicose (em mg/dL) nos dias $-5,0$ e 5

\begin{tabular}{|c|c|c|c|c|c|c|c|}
\hline \multirow[b]{2}{*}{ Dias } & \multirow[b]{2}{*}{ Horas } & \multicolumn{3}{|c|}{ Época do fornecimento } & \multirow[b]{2}{*}{ Média } & \multirow[b]{2}{*}{ CV $(\%)$} & \multirow[b]{2}{*}{ Probabilidade } \\
\hline & & Controle & Ureia antes & Ureia depois & & & \\
\hline \multirow{4}{*}{ D-5 } & $0 \mathrm{~h}$ & 55,05 & 48,23 & 51,02 & 51,37 & 37,9 & 0,5644 \\
\hline & $3 \mathrm{~h}$ & 50,42 & 45,39 & 48,17 & 47,94 & 35,7 & 0,6962 \\
\hline & $6 \mathrm{~h}$ & 42,94 & 45,65 & 44,12 & 44,27 & 30,3 & 0,7503 \\
\hline & Média & 49,47 & 46,43 & 47,77 & 47,86 & 29,7 & 0,8248 \\
\hline \multirow{4}{*}{ D0 } & $0 \mathrm{~h}$ & 51,26 & 48,03 & 53,11 & 50,75 & 36,8 & 0,3907 \\
\hline & $3 \mathrm{~h}$ & 50,66 & 45,61 & 47,65 & 47,93 & 34,4 & 0,6076 \\
\hline & $6 \mathrm{~h}$ & 48,45 & 44,34 & 48,29 & 46,97 & 31,5 & 0,5418 \\
\hline & Média & 50,13 & 46,00 & 49,68 & 48,55 & 31,0 & 0,4255 \\
\hline \multirow{4}{*}{ D5 } & $0 \mathrm{~h}$ & 54,07 & 50,02 & 55,66 & 53,18 & 41,0 & 0,1737 \\
\hline & $3 \mathrm{~h}$ & 57,26 & 52,12 & 53,72 & 54,32 & 44,7 & 0,6205 \\
\hline & $6 \mathrm{~h}$ & 60,55 & 59,19 & 57,93 & 59,22 & 34,8 & 0,9929 \\
\hline & Média & 57,29 & 53,78 & 55,77 & 55,57 & 38,8 & 0,6652 \\
\hline
\end{tabular}


(Tabela 3). Para esta variável, houve efeito de hora de colheita nos dias $-5(\mathrm{P}=0,0233)$ e $5(\mathrm{P}<0,0001)$, mas não no dia $0(P=0,2599)$. Não houve efeito de interação entre dia de colheita e época de fornecimento de ureia $(\mathrm{P}=0,9394)$ e nem efeito de época de fornecimento de ureia no modelo em estudo $(\mathrm{P}=0,5448)$. Entretanto, houve efeito do dia de colheita das amostras $(\mathrm{P}=0,0008)$.

Alguns autores têm reportado que a alta ingestão de $\mathrm{PB}$, que aumenta os níveis sistêmicos de ureia e amônia, está associada ao aumento na glicose plasmática (Visek, 1984; McEvoy et al., 1997), enquanto outros não encontraram efeito da alta ingestão de PB sobre esta variável em novilhas de corte a pasto (Kenny et al., 2001), ou confinadas (Kenny et al., 2002a,b), em novilhas (Sinclair et al., 2000a) ou em vacas leiteiras (Jordan et al., 1983). Concentrações de glicose plasmática superiores a $90 \mathrm{mg} / \mathrm{dL}$ geralmente inibem o desenvolvimento embrionário (Thompson, 1996) e isso pode estar relacionado ao fato de a alta concentração de glicose interferir com a sinalização celular ou alterar o ciclo de Krebs (Boland et al., 2001). Neste trabalho, não houve influência do aumento da PB da dieta sobre os níveis plasmáticos de glicose; houve efeito apenas dos tempos de colheita das amostras (antes, 3 e 6 horas após a alimentação) nos dias -5 e 5, bem como efeito do dia de colheita, com elevação dos teores plasmáticos de glicose entre o dia -5 e o dia 5. De acordo com Kaneko (1989), a concentração de glicose de bovinos é entre 45 e $75 \mathrm{mg} / \mathrm{dL}$ e este dado está em conformidade com este estudo, uma vez que as concentrações de glicose ficaram entre 47 e 58 $\mathrm{mg} / \mathrm{dL}$.

Para os teores de insulina não houve efeito de interação entre dia de colheita e época de fornecimento de ureia $(\mathrm{P}=0,6147)$ (Tabela 4). Entretanto, o dia de colheita $(\mathrm{P}<0,0001)$ influenciou os teores de insulina. Não houve efeito da época de fornecimento de ureia sobre os teores plasmáticos de insulina nos dias $-5,0$ e 5 e nem no modelo estudado $(\mathrm{P}=0,9913)$.

No caso da glicose, há uma grande variabilidade de trabalhos documentando a relação entre ingestão de proteína e insulina sistêmica (Laven \& Drew, 1999), alguns com concentrações elevadas (Blauweikel \& Kincaid, 1986), outras reduzidas (Sinclair et al., 2000a) ou inalteradas (Kenny et al., 2001; Kenny et al., 2002b) em bovinos consumindo alta proteína dietética. Neste trabalho, não foi encontrada influência da época de fornecimento de ureia sobre os níveis séricos de insulina. Entretanto, houve efeito do dia de colheita, com teores de insulina menores no dia 0 , maiores no dia 5 e intermediários no dia -5 . Este comportamento assemelha-se ao da glicose, exceto no dia 0 , que foi intermediário para a glicose e menor para a insulina. As concentrações de insulina em todos os grupos deste trabalho podem ser consideradas baixas (por volta de $10 \mu \mathrm{UI} / \mathrm{mL}$ ) a moderada (por volta de $20 \mu \mathrm{UI} / \mathrm{mL}$ ), segundo Adamiak et al. (2005). Logo, parece não haver relação entre a insulina e o efeito da época de fornecimento de ureia sobre os dados referentes aos embriões.

Para os valores de progesterona não houve efeito de interação entre os dias das coletas e a época de fornecimento de ureia $(\mathrm{P}=0,0623)$, contudo, houve efeito do dia de coleta $(\mathrm{P}<0,0001)$ sobre as concetrações plasmáticas desse hormônio (Tabela 4). Também não foi observado efeito da época de fornecimento de ureia sobre esta variável dias $-5,0$ e 5 nem no modelo de estudo $(\mathrm{P}=0,7161)$.

Como pode ser observado (Tabela 5), não houve efeito da inclusão nem do momento da inclusão de ureia na dieta sobre o total de estruturas recuperadas; de embriões fecundados; de oócitos não-fecundados; de embriões viáveis; e de embriões degenerados. Observações similares sobre ausência de mudanças na morfologia do embrião relacionadas com alto nitrogênio não-proteico foram feitas em outros estudos com vacas não-lactantes (Garcia-Bojalil et al., 1994) e lactantes (Blanchard et al., 1990; Dawuda et al., 2002; Rhoads et al., 2006).

Neste estudo, o fornecimento de ureia após a inseminação reduziu a proporção de oócitos fecundados/ total de estruturas em relação ao fornecimento antes da inseminação ( UD $=50,7$ vs. UA $=75,3 \%$ ), ocasionando diferença de $32,7 \%$ na proporção de oócitos fecundados/

Tabela 4 - Teores de insulina em ì UI/mL e de progesterona em ng/mL nos dias $-5,0$ e 5

\begin{tabular}{|c|c|c|c|c|c|c|c|}
\hline & \multirow[b]{2}{*}{ Dias } & \multicolumn{3}{|c|}{ Época de fornecimento } & \multirow[b]{2}{*}{ Média } & \multirow[b]{2}{*}{$\mathrm{CV}(\%)$} & \multirow[b]{2}{*}{ Probabilidade } \\
\hline & & Controle & Ureia antes & Ureia depois & & & \\
\hline \multirow[t]{3}{*}{ Insulina } & D- 5 & 14,17 & 14,85 & 12,37 & 13,82 & 62,7 & 0,8013 \\
\hline & D0 & 12,69 & 10,16 & 10,51 & 11,10 & 60,3 & 0,8137 \\
\hline & D5 & 19,52 & 18,80 & 18,92 & 19,07 & 74,0 & 0,7348 \\
\hline \multirow[t]{3}{*}{ Progesterona } & $D-5$ & 1,40 & 0,56 & 0,92 & 0,95 & 110,8 & 0,0830 \\
\hline & D0 & 0,18 & 0,25 & 0,27 & 0,24 & 79,8 & 0,5175 \\
\hline & D5 & 10,59 & 10,76 & 6,36 & 9,27 & 107,5 & 0,2615 \\
\hline
\end{tabular}


total de estruturas entre as épocas de fornecimento de ureia. Embora essa diferença numérica não seja significativa, a constatação da tendência sugerida pelos valores numéricos pode ter sido comprometida pelo elevado coeficiente de variação da variável.

Reduções nas porcentagens de oócitos fecundados sobre o total de recuperados em animais recebendo dietas com alta proteína degradável no rúmen foram reportados em vacas superovuladas (Blanchard et al., 1990) e em ovelhas (Bishonga et al., 1996).

Houve tendência de efeito $(\mathrm{P}=0,0522)$ do momento de inclusão da ureia na dieta sobre a relação entre o total de embriões viáveis e o total de estruturas recuperadas.O fornecimento de ureia após a inseminação reduziu a relação embriões viáveis sobre o total de estruturas recuperadas em comparação ao fornecimento antes da inseminação
$(\mathrm{UD}=39,4$ vs. $\mathrm{UA}=73,2 \%)$, com redução de 46,2\% Entretanto, essa redução não é causada pela diminuição da viabilidade dos embriões fecundados no grupo que recebeu ureia após a inseminação, mas é resultante da maior relação de não-fecundados sobre o total de estruturas recuperadas deste grupo em relação aos demais $(\mathrm{C}=17,8 ; \mathrm{UA}=24,7$ e $\mathrm{UD}=49,3 \%)$, que pode ser comprovada pela relação embriões viáveis sobre o total de fecundados $(\mathrm{C}=85,5$; $\mathrm{UA}=89,4$ e $\mathrm{UD}=87,1 \%)$, cujos valores foram bem próximos.

Os efeitos negativos nos embriões não parecem estar ligados à progesterona sérica, já que não houve efeito da época de fornecimento de ureia sobre essa variável. Os resultados corroboram uma série de trabalhos com novilhas de corte (Kenny et al., 2001; Kenny et al., 2002a; Kenny et al., 2002b), novilhas leiteiras (Elrod \& Butler, 1993), vacas

Tabela 5 - Número médio de estruturas recuperadas e sua classificação em números absolutos e em porcentagem do total de estruturas recuperadas, fecundadas e viáveis

\begin{tabular}{|c|c|c|c|c|c|c|c|}
\hline \multirow[t]{2}{*}{ Estruturas/animal } & \multicolumn{3}{|c|}{ Época de fornecimento } & \multirow[b]{2}{*}{ Média } & \multirow[b]{2}{*}{$\mathrm{CV}$} & \multicolumn{2}{|c|}{ Probabilidade } \\
\hline & Controle & Ureia antes & Ureia depois & & & $\mathrm{C}_{1}^{\mathrm{a}}$ & $\mathrm{C}_{2}{ }^{\mathrm{b}}$ \\
\hline Total estrutura ${ }^{\mathrm{c}}\left(\mathrm{n}^{\mathrm{o}}\right)^{\mathrm{d}}$ & 3,15 & 3,72 & 4,10 & 3,66 & 114,3 & 0,5850 & 0,4632 \\
\hline Total fecundado ${ }^{\mathrm{e}}\left(\mathrm{n}^{\mathrm{o}}\right)$ & 2,35 & 2,75 & 2,48 & 2,52 & 126,0 & 0,8394 & 0,2282 \\
\hline$(\% \text { total })^{\mathrm{f}}$ & 82,2 & 75,3 & 50,7 & 68,5 & 58,6 & 0,1229 & 0,0678 \\
\hline Não-fecundado $\left(\mathrm{n}^{\mathrm{o}}\right)$ & 0,91 & 1,00 & 1,83 & 1,26 & 181,5 & 0,1138 & 0,3206 \\
\hline Viávelg $\left(n^{\circ}\right)$ & 2,24 & 2,48 & 2,00 & 2,24 & 126,0 & 0,8595 & 0,4472 \\
\hline$(\%$ total $)$ & 75,8 & 73,2 & 39,4 & 61,8 & 66,0 & 0,2872 & 0,0522 \\
\hline$(\% \text { fecundado })^{\mathrm{h}}$ & 85,5 & 89,4 & 87,1 & 87,4 & 28,5 & 0,2868 & 0,3101 \\
\hline Inviável ${ }^{\mathrm{i}}\left(\mathrm{n}^{\mathrm{o}}\right)$ & 0,43 & 0,23 & 0,52 & 0,39 & 213,0 & 0,5825 & 0,5738 \\
\hline$(\%$ total $)$ & 6,4 & 2,2 & 11,3 & 6,6 & 250,0 & 0,2540 & 0,3324 \\
\hline (\% fecundado) & 65,8 & 62,5 & 30,6 & 54,5 & 77,0 & 0,0961 & 0,0472 \\
\hline$(\% \text { viável })^{\mathrm{j}}$ & 76,9 & 68,8 & 38,6 & 63,5 & 64,3 & 0,0134 & 0,0184 \\
\hline Blastocisto inicial $\left(\mathrm{n}^{\mathrm{o}}\right)$ & 0,41 & 0,57 & 0,87 & 0,62 & 183,5 & 0,5385 & 0,3400 \\
\hline$(\%$ total $)$ & 12,2 & 17,8 & 17,3 & 16,0 & 180,5 & 0,8491 & 0,4837 \\
\hline (\% fecundado) & 18,5 & 21,2 & 32,3 & 23,4 & 148,7 & 0,5746 & 0,1392 \\
\hline (\% viável) & 21,8 & 22,9 & 42,0 & 27,7 & 139,9 & 0,5512 & 0,1592 \\
\hline Blastocisto $\left(\mathrm{n}^{\mathrm{o}}\right)$ & 0,14 & 0,13 & 0,43 & 0,24 & 375,3 & 0,8044 & 0,1864 \\
\hline$(\%$ total $)$ & 1,2 & 4,0 & 6,8 & 4,2 & 313,3 & 0,5824 & 0,3343 \\
\hline (\% fecundado) & 1,2 & 5,8 & 15,5 & 7,0 & 270,9 & 0,4024 & 0,2108 \\
\hline (\% viável) & 1,4 & 8,3 & 19,4 & 8,8 & 270,8 & 0,3749 & 0,2469 \\
\hline
\end{tabular}

${ }^{a} C_{1}=$ primeiro contraste ortogonal: efeito da inclusão de ureia [C vs. (UA + UD)]; ${ }^{b} \mathrm{C}_{2}=$ segundo contraste ortogonal: efeito do momento da inclusão de ureia (UA vs. UD) ${ }^{\mathrm{c}}$ Total de estruturas recuperadas = oócitos fecundados + não-fecundados; ${ }^{\mathrm{d}}$ Número absoluto; ${ }^{\mathrm{e}}$ Total de estruturas fecundadas $=$ Embriões viáveis + Inviáveis; ${ }^{\mathrm{f}}$ Porcentagem sobre o total de estruturas recuperadas por animal; ${ }^{\mathrm{g}}$ Viáveis $=$ mórula compacta + blastocisto inicial + blastocisto + blastocisto expandido; ${ }^{\mathrm{h}}$ Porcentagem sobre o total de estruturas fecundadas por animal; ${ }^{\mathrm{i}}$ Inviáveis = embriões degenerados; ${ }^{\mathrm{j}}$ Porcentagem sobre total de estruturas viáveis por animal. 
não-lactantes (Blauweikel \& Kincaid, 1986; Garcia-Bojalil et al., 1994) e em ovelhas (McEvoy et al., 1997), nos quais não foi encontrado nenhum efeito do alto NUP sobre a concentração sistêmica de progesterona.

Trabalhos têm elucidado a relação da diminuição nos hormônios esteroidais circulantes em vacas em lactação submetidas à alta ingestão de MS (Sangsritavong et al., 2002; Vasconcelos et al., 2003). Esses estudos associam alto consumo de MS e aumento no fluxo sanguíneo hepático em vacas leiteiras ao aumento do metabolismo dos hormônios esteroides. Logo, pode ocorrer confundimentos nos resultados quando se relacionam vacas leiteiras em produção e níveis sistêmicos de progesterona. Neste trabalho isolou-se o efeito da alta proteína dietética sobre o desempenho reprodutivo de vacas não-lactantes e bem nutridas, provavelmente em balanço energético positivo. Assim, a ausência de efeito da época de fornecimento de ureia sobre a concentração de progesterona permite inferir que o aumento da proteína degradável no rúmen nas dietas parece não ter efeito direto sobre a concentração de progesterona.

No entanto, a menor proporção de oócitos fecundados/ total de estruturas, com a elevação do teor de PB no grupo que recebeu ureia após a inseminação iniciada no dia $0 \mathrm{e}$ mantido até o dia 5, pode ser associada ao efeito do alto NUP restrito a determinado momento. Esse resultado é condizente com a teoria de que o efeito prejudicial do alto NUP esteja restrito à fase de maturação do oócito e o desenvolvimento inicial do embrião.

Altas concentrações de ureia ou amônia impedem a meiose durante a fase de maturação (De Wit et al., 2001), diminuem a taxa de clivagem (Hammon et al., 2000; Sinclair et al., 2000b; Ocon \& Hansen, 2003), reduzem o desenvolvimento ao estágio de blastocisto in vitro (Gardner \& Lane, 1993; Lane \& Gardner, 1994; Hammon et al., 2000; De Wit et al., 2001) e a produção e a qualidade de embriões in vivo (Dawuda et al., 2002). Além disso, a amônia causa diminuição na taxa de crescimento de células da granulosa, provoca aumento no metabolismo proteico celular (Rooke et al., 2004) e altera o pH intracelular do oócito (Bem-Yosef \& Shalgi, 1998).

Embriões na fase inicial de clivagem (estágio de précompactação, entre zigoto e 2 células ou entre 2 e 8 células) são mais suscetíveis aos efeitos da alta concentração de amônia e/ou ureia (Zander et al., 2006).

Neste trabalho, houve efeito da inclusão da ureia na dieta nas relações mórulas compactas sobre o total de estruturas recuperadas $(\mathrm{P}=0,0132)$ e sobre o total de embriões viáveis $(\mathrm{P}=0,0138)$. Também houve efeito da época da inclusão da ureia na dieta nas relações mórulas compactas sobre total de estruturas recuperadas $(\mathrm{P}=0,0117)$, no total de oócitos fecundados ( $\mathrm{P}=0,0472)$ e no total de embriões viáveis $(\mathrm{P}=0,0184)$. Estes efeitos, em ambos os casos, são causados pelas menores relações de mórulas compactas no grupo que recebeu ureia após a inseminação em relação aos demais. Em análise da relação de mórulas compactas sobre o total de embriões viáveis $(\mathrm{C}=76,9$; $\mathrm{UA}=68,8 \mathrm{e}$ $\mathrm{UD}=38,6 \%$ ), esta menor proporção de mórulas no grupo que recebeu ureia após a inseminação pode ter sido causada pela maior proporção de blastocistos iniciais $(\mathrm{C}=21,8 ; \mathrm{UA}=22,9$ e UD $=42,0 \%)$ e blastocistos $(\mathrm{C}=1,4$; $\mathrm{UA}=8,3$ e $\mathrm{UD}=19,4 \%)$ sobre o total de viáveis do grupo que recebeu ureia após a inseminação em relação ao fornecimento anterior e ao controle, embora não seja significativo para estas duas últimas relações. Com isso, o desenvolvimento embrionário pode ter sido mais acelerado no grupo que recebeu ureia após a inseminação.

Os resultados são condizentes com a teoria de que altas concentrações de amônia e ureia acarretam maior metabolismo energético (McEvoy et al., 1997) proteico (Sinclair et al., 2000b) e, também, em aceleração do crescimento embrionário (Hammon et al., 2000; Berardinelli et al., 2001). Berardinelli et al. (2001) afirmaram que alterações no desenvolvimento dos embriões causadas pela alta proteína degradável no rúmen da dieta, ou seja, embriões mais maduros antes da entrada no útero, podem levar a uma assincronia entre mudanças uterinas e mudanças embrionárias necessárias para o reconhecimento materno da gestação e posterior desenvolvimento embrionário. Nesse estado, os embriões podem ser mais suscetíveis ao $\mathrm{pH}$ uterino adverso induzido pela alta concentração sistêmica de ureia.

Pode-se afirmar que o efeito negativo do alto NUP sobre a eficiência reprodutiva parece estar restrito entre a fase de maturação dos oócitos e o desenvolvimento inicial do embrião, ou seja, até o dia 7 (dia $0=$ estro). Neste trabalho, esse efeito foi encontrado principalmente entre a fase de maturação e a fertilização do oócito. Além disso, os embriões que sofreram o efeito do alto NUP nesta fase parecem ter o desenvolvimento mais acelerado.

Os resultados verificados, de menor proporção de oócitos fecundados em relação ao total de estruturas recuperadas e de desenvolvimento embrionário mais acelerado, podendo causar assincronia entre embrião e útero, por efeitos ocorridos entre o dia 0 e o dia 5 do ciclo, podem ser incluídos na responsabilidade pela diminuição do desempenho reprodutivo dos ruminantes reportados nos últimos 30 anos (Jordan \& Swanson, 1979; Jordan et al., 1983; Blanchard et al., 1990; Butler et al., 1996; 
Robinson, 1996; O’Callaghan \& Boland, 1999; Butler, 2000; Dawuda et al., 2002; Powell et al., 2006; Tamminga, 2006).

Buscando uma explicação para estes efeitos, Laven et al. (2007) concluíram que vacas são capazes de se adaptar a dietas contendo alto nitrogênio. Entretanto, estas dietas podem causar redução da fertilidade quando introduzidas em períodos críticos, por exemplo, de inseminação, o que não ocorre quando introduzidas em estágios mais iniciais. De Wit et al. (2001) sugeriram a adoção da prática de promover a redução da ingestão de proteína durante o período de inseminação para melhorar as taxas de concepção.

A falta de outros resultados significativos sobre o desempenho reprodutivo das vacas pode estar relacionada à pouca variação do NUP entre as épocas de fornecimento de ureia, principalmente no D-5 e no D5, uma vez que as dietas contendo NNP não produziram diferenças no NUP em relação à controle.

\section{Conclusões}

O fornecimento de dieta contendo ureia (100 g/animal/dia) sem adaptação a vacas Nelore superovuladas, com início seis dias antes da inseminação, não tem qualquer efeito sobre os parâmetros reprodutivos, mesmo em elevadas concentrações de nitrogênio ureico plasmático. Entretanto, quando o fornecimento da mesma dieta é iniciado na inseminação (dia 0) e mantido por 6 dias, sem adaptação, ocorre aumento da concentração de nitrogênio ureico plasmático e também parece haver aceleração do desenvolvimento embrionário inicial. A concentração de progesterona parece não sofrer efeitos nem da inclusão nem do momento da inclusão da ureia na dieta e não aparenta relação com a viabilidade embrionária. Da mesma forma, as concentrações de glicose e insulina não são afetadas pelo fornecimento e nem pelo momento de inclusão de ureia na dieta.

\section{Agradecimentos}

À Fundação de Amparo à Pesquisa do Estado de São Paulo (FAPESP), pelo auxílio financeiro a este projeto e à Coordenação de Aperfeiçoamento de Pessoal de nível superior (CAPES), pela bolsa fornecida ao primeiro autor. Ao Laboratório de Fisiologia da Lactação (Departamento de Ciências Básicas - Faculdade de Zootecnia e Engenharia de Alimentos - USP) e ao Laboratório de Endocrinologia (Departamento de Apoio, Produção e Saúde Animal Faculdade de Odontologia de Araçatuba - UNESP).

\section{Referências}

ADAMIAK, S.J.; MACKIE, K.; WATT, R.G. et al. Impact of nutrition on oocyte quality: cumulative effects of body condition and diet leading to hyperinsulinemia in cattle. Biology of Reproduction, v.73, n.5, p.918-926, 2005.

BARUSELLI, O.S.; SÁ FILHO, M.F.; MARTINS, C.M. et al. Superovulation and embryo transfer in Bos indicus cattle. Theriogenology, v.65, n.1, p.77-88, 2006.

BEN-YOSEF, D.; SHALGI, R. Early ionic events in activation of the mammalian egg. Reviews of Reproduction, v.3, n.2, p.96-103, 1998 .

BERARDINELLI, J.G.; WENG, J.; BURFENING, P.J. et al. Effect of excess degradable intake protein on early embryonic development, ovarian steroids, and blood urea nitrogen on days $2,3,4$, and 5 of the estrous cycle in mature ewes. Journal of Animal Science, v.79, n.1, p.193-199, 2001.

BISHONGA, C.; ROBINSON, J.J.; McEVOY, T.G. et al. Excess dietary urea intake in ewes and its effects on ovulation rate and embryo development. Japanese Journal of Veterinary Research, v.44, n.3, p.139-151, 1996.

BLANCHARD, T.; FERGUNSON, J.; LOVE, L. et al. Effect of dietary crude-protein type on fertilization and embryo quality in dairy cattle. American Journal of Veterinary Research, v. 51, n.6, p.905-908, 1990 .

BLAUWEIKEL, R.; KINCAID, R.L. Effect of crude protein and solubility on performance and blood constituents of dairy cows. Journal of Dairy Science, v.69, n.8, p.2091-2098, 1986.

BOLAND, M.P.; LONERGAN, P.; O'CALLAGHAN, D. Effect of nutrition on endocrine parameters, ovarian physiology, and oocyte and embryo development. Theriogenology, v.55, n.6, p.1323-1340, 2001

BUTLER, W.R. Nutritional interactions with reproductive performance in dairy cattle. Animal Reproduction Science, v.60-61, p.449-457, 2000

BUTLER, W.R.; CALAMAN, J.J.; BEAM, S.W. Plasma and milk urea nitrogen in relation to pegnancy rate in lactating dairy cattle. Journal of Animal Science, v.74, n.4, p.858-865, 1996.

DAWUDA, P.M,; SCARAMUZZI, R.J.; LEESE, H.J. et al. Effect of timing of urea feeding on the yield and quality of embryos in dairy cows. Theriogenology, v.58, n.8, p.1443-1455, 2002.

DE WIT, A.A.C.; CESAR, M.L.F.; KRUIP, T.A.M. Effect of urea during in vitro maturation on nuclear maturation and embryo development of bovine cumulus-oocyte-complexes. Journal of Dairy Science, v. 84, n.8, p.1800-1804, 2001.

ELROD, C.C.; BUTLER, W.R. Reduction of fertility and alteration of uterine $\mathrm{pH}$ in heifers fed excess ruminally degradable protein. Journal Animal Science, v.71, n.3 p.694-701, 1993.

GARCIA-BOJALIL, C.M.; STAPLES, C.R.; THATCHER, W.W et al. Protein intake and development of ovarian follicles and embryos of superovulated nonlactating dairy cows. Journal of Dairy Science, v.77, n.9, p.2537-2548, 1994.

GARDNER, D.K.; LANE, M. Amino acids and ammonia regulate mouse embryo development in culture. Biology of Reproduction, v.48, n.2, p.377-385, 1993.

HALLET, C.J.; COOK, J.G.H. Reduced nicotinamide adenine dinucleotide-coupled reaction for emergency blood urea estimation. Clinica Chimica Acta, v.35, n.1, p.33-37, 1971.

HAMMON, D.S.; WANG, S.; HOLYOAK, G.R. Effects of ammonia on development and viability of preimplantation bovine embryos. Animal Reproduction Science, v.59, n.1-2, p.23-30, 2000.

HENRY, R.J. Clinical chemistry: principles and techniques. New York; Harper \& Row, 1968. 550p.

HENRY, R.J.; CANNON, D.C.; WINKELMAN, J. Clinical chemistry: principles and techniques. 2.ed. New York: Harper \& Row Publishers, 1974. p.1288. 
JORDAN, E.R.; CHAPMAN, T.E.; HOLTAN, D.W. et al. Relationship of dietary crude protein to composition of uterine secretions and blood in high-producing postpartum dairy cows. Journal of Dairy Science, v.66, n.9, p.1854-1861, 1983.

JORDAN, E.R.; SWANSON, L.V. Effect of crude protein on reproductive efficiency, serum total protein, and albumin in the high-producing dairy cow. Journal of Dairy Science, v.62, n.1, p.58-63, 1979.

KANEKO, J.J. Appendixes. In: KANEKO, J.J. (Ed.) Clinical biochemistry of domestic animals. 4.ed. San Diego: Academic Press, 1989. p.877-901.

KENNY, D.A; BOLAND, M.P.; DISKIN, M.G. et al. Effect of pasture crude protein and fermentable energy supplementation on blood metabolite and progesterone concentrations and on embryo survival in heifers. Animal Science, v.73, n.3, p.501-512, 2001 .

KENNY, D.A.; BOLAND, M.P.; DISKIN, M.G. et al. Effect of rumen degradable protein with or without fermentable carbohydrate supplementation on blood metabolites and embryo survival in cattle. Animal Science, v.74, n.3, p.529-537, 2002a.

KENNY, D.A.; HUMPHERSON, P.G.; LEESE, H.J. et al. Effected of elevated systemic concentrations of ammonia and urea on the metabolite and ionic composition of oviductal fluid in cattle. Biology of Reproduction, v.66, n.6, p.1797-1804, 2002b.

LANE, M.; GARDNER, D.K. Increase in postimplantation development of cultured mouse embryos and induction of fetal retardation and exencephaly by ammonium ions. Journal of Reproduction and Fertility, v.102, p.305-312, 1994.

LAVEN, R.A.; DREW, S.B. Dietary protein and the reproductive performance of cows. The Veterinary Record, v.145, n.24, p.687-695, 1999.

LAVEN, R.A.; SCARAMUZZI, R.J.; WATHES, D.C. Recent research on the effects of excess dietary nitrogen on the fertility of dairy cows. The Veterinary Record, v.160, n.11, p.359-362, 2007.

MCEVOY, T.G.; ROBINSON, J.J.; AITKEN, R.P. et al. Dietary excesses of urea influence the viability and metabolism of preimplantation sheep embryos and may affect fetal growth among survivors. Animal Reproduction Science, v.47, n.1-2, p.71-90, 1997.

MORAES, E.H.B.K.; PAULINO, M.F.; MORAES, K.A.K. et al. Uréia em suplementos protéico-energéticos para bovinos de corte durante o período da seca: características nutricionais e ruminais. Revista Brasileira de Zootecnia, v.38, n.4, p.770-777, 2009.

NATIONAL RESEARCH COUNCIL - NRC. Nutrient requirements of beef cattle. 7.ed. Washington, D.C.: National Academy Press, 1996. 242p.

O'CALLAGHAN, D.O.; BOLAND, M.P. Nutritional effects on ovulation, embryo development and the establishment of pregnancy in ruminants. Animal Science, v.68, n.2, p.299-314, 1999.

OCON, O.M.; HANSEN, P.J. Disruption of bovine oocytes and preimplantation embryos by urea and acidic pH. Journal of Dairy Science, v.86, n.4, p.1194-1200, 2003.

POWELL, K.; ROOKE, J.A.; MCEVOY, T.G. et al. Zygote donor nitrogen metabolism and in vitro embryo culture perturbs in utero development and IGF2R expression in ovine fetal tissues. Theriogenology, v.66, n.8, p.1901-1912, 2006.

RHOADS, M.L.; GILBERT, R.O.; LUCY, M.C. et al. Effects of urea infusion on the uterine luminal environment of dairy cows. Journal of Dairy Science, v.87, n.9, p.2896-2901, 2004.
RHOADS, M.L.; RHOADS, R.P.; GILBERT, R.O. et al. Detrimental effects of high plasma urea nitrogen levels on viability of embryos from lactating dairy cows. Animal Reproduction Science, v.91, n.1-2, p.1-10, 2006.

ROOKE, J.A.; EWEN, M.; MACKIE, K. et al. Effect of ammonium chloride on the growth and metabolism of bovine ovarian granulosa cells and the development of ovine oocytes matured in the presence of bovine granulosa cells previously exposed to ammonium chloride. Animal Reproduction Science, v.84, n.1, p.53-71, 2004.

SANGSRITAVONG, S.; COMBS, D.K.; SARTORI, R. et al. High feed intake increases liver blood flow and metabolism of progesterone and estradiol-17ß in dairy cattle. Journal of Dairy Science, v.85, n.11, p.2831-2842, 2002.

STAPLES, C.R.; GARCIA-BOJALIL, C.M.; OLDICK, B.S. et al. Protein intake and reproductive performance of dairy cows: a review, a suggested mechanism, and blood and milk urea measurements. In: ANNUAL FLORIDA RUMINANT NUTRITION SYMPOSIUM, 4., 1993, Gainesville. Proceedings... Gainesville: University of Flórida, 1993. p.37-51.

RENNÓ, L.N.; VALADARES FILHO, S.C.; PAULINO, M.F. et al. Níveis de uréia na ração de novilhos de quatro grupos genéticos: parâmetros ruminais, uréia plasmática e excreções de uréia e creatinina. Revista Brasileira de Zootecnia, v.37, n.3, p.556-562, 2008.

ROBINSON, J.J. Nutrition and reproduction. Animal Reproduction Science, v.42, n.1, p.25-34, 1996.

SINCLAIR, K.D.; KURAN, M.; GEBBIE, F.E. et al. Nitrogen metabolism and fertility in cattle: II. Development of oocytes recovered from heifers offered diets differing in their rate of nitrogen release in the rumen. Journal of Animal Science, v.78, n.10, p.2670-2680, 2000b.

SINCLAIR, K.D.; SINCLAIR, L.A.; ROBINSON, J.J. Nitrogen metabolism and fertility in cattle: I. Adaptive changes in intake and metabolism to diets differing in their rate of energy and nitrogen release in the rumen. Journal of Animal Science, v.78, n.10, p.2659-2669, 2000a.

STATISTICAL ANALISYS SYSTEM - SAS. SAS/STAT User's guide. 8.ed. Cary: SAS, 2001. 441p.

STRINGFELLOW, D.A.; SEIDEL, S.M. Manual da Sociedade Internacional de Transferência de Embriões. 3.ed. Savoy: IETS, 1998. 180p.

TAMMINGA, S. The effect of the supply of rumen degradable protein and metabolisable protein on negative energy balance and fertility in dairy cows. Animal Reproduction Science, v.96, n.3-4, p.227-239, 2006

THOMPSON, J.G. Defining the requirements for bovine embryo culture. Theriogenology, v.45, n.1, p.27-40, 1996.

TRINDER, R. Determination of glucose in blood using glucose oxidase with an alternative oxygen acceptor. Annals of Clinical Biochemistry, v.6, p.24-27, 1969.

VASCONCELOS, J.L.M.; SANGSRITAVONG, S.; TSAI, S.J. et al. Acute reduction in serum progesterone concentrations after feed intake in dairy cows. Theriogenology, v. 60, n. 5 , p.795-807, 2003.

VISEK, W.J. Ammonia: It's effects on biological systems, metabolic hormones, and reproduction. Journal of Dairy Science, v.67, n.3, p.481-498, 1984.

ZANDER, D.L.; THOMPSON, J.G.; LANE, M. Pertubations in mouse embryo development and viability caused by ammonium are more severe after exposure at the cleavage stages. Biology of Reproduction, v.74, n.2, p.288-294, 2006. 